International Journal of Current Advanced Research

ISSN: O: 2319-6475, ISSN: P: 2319 - 6505, Impact Factor: SJIF: 5.995

Available Online at www.journalijcar.org

Volume 6; Issue 4; April 2017; Page No. 3225-3228

DOI: http://dx.doi.org/10.24327/ijcar.2017.3228.0231

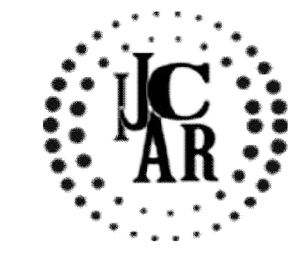

Research Article

\title{
COMPARATIVE STUDY OF TOPICAL EFFECTS OF PROBIOTICS WITH A COMMERCIAL FLUORIDE TOOTH PASTE IN REDUCING DENTAL CARIES IN PATIENTS WITH HIGHER SALIVARY STREPTOCOCCUS MUTANS LEVELS
}

\author{
Nandhini $V^{1}{ }^{*}$, Santhosh Kumar²., Musthafa ${ }^{3}$ and Gayathri $S^{4}$ \\ 1,4Sathyabama University Dental College\& Hospital, Chennai \\ ${ }^{2}$ DR Santhosh Dental Organisation, Chennai \\ ${ }^{3}$ General Practioner R. D. Dental Care
}

\begin{tabular}{l}
\hline A R T I C L E I N F O \\
Article History: \\
Received $11^{\text {th }}$ January, 2017 \\
Received in revised form $19^{\text {th }}$ February, 2017 \\
Accepted $22^{\text {nd }}$ March, 2017 \\
Published online $28^{\text {th }}$ April, 2017 \\
\hline
\end{tabular}

Key words:

Probiotics, fluoride tooth paste, anticaries effect.

\begin{abstract}
A B S T R A C T
Background: WHO defines probiotics as 'live microorganisms which, when administered in adequate amounts, confer a health benefit to the host'. Traditionally, probiotics have prevented and treated gastro intestinal diseases. In the last 15 years, there has been increasing interest of a possible probiotic impact on the oral microbiota and dental caries. Aim: Aim of the present study is to study the impact of selected strain of probiotic lactobacilli in caries prone individuals by analyzing salivary $\mathrm{pH}$ changes, Streptococcus mutans colony forming units before and after consumption of probiotic in form of tooth paste.

Methodology: 30 patients with similar DMF index and $\mathrm{pH}<6.8$ were selected and divided in to 3 groups Group A, group B and group C and were instructed to use probiotic tooth paste, fluoridated tooth paste and placebo tooth paste (indigenous preparation) for a period of 2 weeks respectively. Salivary swabs were collected at baseline and at 15 days time. Both stimulated and unstimulated salivary samples are also collected for microbial analysis.

Results: Growth inhibition capacity of Probiotic lactobacillus species has been found statistically significant in both the study groups with $p$ value 0.001 in probiotic group and $\mathrm{p}$ value 0.006 in fluoride group. While placebo group yielded statistically insignificant $p$ value of 0.086. Intergroup comparison revealed no significance. Acidogenic potential between probiotic and fluoride toothpaste, showed significant reduction in acidogenicity with $\mathrm{p}$ value 0.04 individually. But in inter group comparison, efficiency is same with $\mathrm{p}$ value 0.5 .

Conclusion: Probiotics are potential candidates to replace fluoride in tooth paste composition, in years to come. More clinical trials done with different age group and larger population is required to substantiate
\end{abstract}

Copyright $(02017$ Nandhinim V et al. This is an open access article distributed under the Creative Commons Attribution License, which permits unrestricted use, distribution, and reproduction in any medium, provided the original work is properly cited.

\section{INTRODUCTION}

The oral cavity is the beginning of the gastrointestinal tract and provides different and varying habitats for bacteria as it consists of both soft shedding tissues of the mucosa (mucosa, tongue, cheek, palate) and hard non-shedding surfaces (teeth) tissues, which are all embedded in saliva. Our understanding with regard to the effect of microbes on human health has gradually developed from pathogens inducing infections to a mutually beneficial interaction with indigenous microorganisms that contribute to normal human physiology and immune homeostasis. The microflora in the oral cavity does not itself cause diseases as long as it exists in equilibrium and in balance with the host. ${ }^{1}$

${ }^{*}$ Corresponding author: Nandhinim $\mathbf{V}$

Sathyabama University Dental College\& Hospital, Chennai
Dental caries is a multifactorial disease, causative factor being a shift from a balanced microflora to a microflora that includes more aciduric species such as Streptococcus mutans and non-mutans streptococci.

In the last 15 years, several in vitro and in vivo studies have been conducted on possible effects of probiotic bacteria in the oral cavity. When used as an oral probiotic, it is desirable that the bacteria have the ability to survive in saliva. Some commonly used probiotic lactobacilli can interfere with Streptococcus mutans biofilm formation and probiotic lactobacilli can inhibit the adherence of Streptococcus mutans to hydroxyapatite. ${ }^{2,3}$ The present study aims to investigate whether selected strains of probiotic lactobacilli interact with Streptococcus mutans and Streptococcuc mitis and to study the impact of probiotic lactobacilli in caries prone individuals by analyzing salivary $\mathrm{pH}$ changes, Streptococcus mutans \& 
Streptococcus mitis colony forming units before and after consumption of probiotic in form of tooth paste.

\section{METHODOLOGY}

\section{Materials Used}

1. Probiotic toothpaste preparation.

2. Commercial Fluoride tooth paste.

3. Non fluoride tooth paste.

4. GC's Saliva-Check Buffer kit's - contains pH test strips, Saliva dispensing cups, Wax gum pieces for saliva stimulation, Saliva dispensing pipettes \& Buffer test strips

5. Plaque $\mathrm{pH}$ indicator

6. Sterile $15-\mathrm{mL}$ polyethylene (PE) tube

7. Culture medium: Mitis-Salivarius Bacitracin Agar (MSB) or Trypticase-Yeast-Extract-Cysteine- SucroseBacitracin Agar (TYCSB)

Thirty patients between age group 18-40 years are to be selected. Patients who has higher DMF index and Salivary Streptococcus mutans count $>10^{5}$ are selected and divided in to 3 groups randomly,

Group A: [10 patients] Probiotic tooth paste

\section{Probiotic tooth paste preparation}

Spores of Lactic acid bacillus is used for preparation of probiotic tooth paste. Commercially available probiotic, Capsule. Bifilac forte is used. Tooth paste preparation is being done in collaberation with JNM pharma R\&D Department, crompet, chennai. 200million spores of lactic acid bacillus (A07FA01) is being incorporated with customized tooth paste preparation and packed in a aluminium pack 50 grams. Spores of lactobacillus viability in tooth paste are being confirmed by invitro colony count test.

Group B: 10 patients Fluoridated tooth paste

Group C: 10 patients Non fluoridated tooth paste.

All patients were instructed to brush twice daily with tooth paste for a period of two weeks. They were also instructed not to use any commercial mouthwash products and not to consume any probiotic food products during study period. Unstimulated and stimulated salivary samples are collected before the study, at the end of two week study period. Salivary $\mathrm{pH}$ of stimulated and unstimulated saliva ware also assessed. Patients are instructed to chew non flavoured chewing gum and expectorate saliva into a sterile $10-\mathrm{mL}$ graduated cup every 1 minute for total of 5 minutes. To overcome saliva flow rate and composition alterations during different hours of day samples are collected between 9:30 and 10:30 a.m. for all subjects.

Microbiological analyses were commenced within $45 \mathrm{~min}$ after sample collection. The Mitis Salivarius Bacillus agar medium which was used for the detection and quantification is selective for mutans streptococci. The medium contains Bacitracin, which is an antibiotic selective for mutans streptococci among other bacteria. The plates were incubated anaerobically at $37{ }^{0} \mathrm{C}$ for 5 days and $\mathrm{CFU} / \mathrm{mL}$ of saliva determined.
The colony forming units (CFU) were analysed and Streptococcus mutans concentration in saliva was expressed as $\log 10 \mathrm{CFU} / \mathrm{ml}$.

\section{Statistical Methods}

The data were processed with the Statistical Package for Social Sciences. With the group comparison was done using Wilcoxon signed rank test and inter group comparison was done using Mann Whitney $U$ test and $p$ value $<0.05$ was considered to be statistically significant.

\section{RESULTS}

All 30 subjects were enrolled, randomized and completed the trial. All Patients were selected from the out patient ward of Ragas dental college and hospital and who has higher DMF index and Salivary Streptococcus mutans count $>10^{5}$. No adverse events occurred in any group. For all groups the toothpaste acceptability was rated good. The present study shows significant reduction in Streptococcus mutans CFU/ml, from 103 at baseline to 34 after 15 days application in group A (p value - 0.006) and from 125 at baseline to 32 after 15 days application in group B ( $p$ value - 0.001). But in group C there was no significant reduction in S.mutans $\mathrm{CFU} / \mathrm{ml}$ with $\mathrm{p}$ value - 0.086 (Table 1)

Table 1 Colony Count of S.mutans in $10^{-4}$ dilution

\begin{tabular}{cccc}
\hline Groups & Sample time & Mean CFU & P values \\
\hline Probiotic & Baseline & 125.00 & $\mathrm{p}=0.001$ \\
group & 15 days & 32.40 & \\
Fluoride & Baseline & 103.60 & $\mathrm{p}=0.006$ \\
group & 15th days & 34.50 & $\mathrm{p}=0.086$ \\
placebo & Baseline & 111.60 & $\mathrm{p}=0.00$ \\
group & 15 days & 97.00 & \\
\hline
\end{tabular}

The present study shows significant change in $\mathrm{pH}$ of unstimulated saliva from 6.66 at baseline to 6.96 after 15 days application ( $\mathrm{p}$ value -0.004 ) and $\mathrm{pH}$ of stimulated saliva from 7.04 at baseline to 7.38 after 15 days application ( $p$ value 0.004 ) in group A. In group B also there was a significant change in $\mathrm{pH}$ of unstimulated saliva from 6.64 at baseline to 6.98 after 15 days application (p value - 0.004) and $\mathrm{pH}$ of stimulated saliva from 6.84 at baseline to 7.30 after 15 days application ( $\mathrm{p}$ value - 0.004). Whereas in group $\mathrm{C}$ there was no significant changes in the $\mathrm{pH}$ of stimulated and the unstimulated saliva (Table 2).

Table 2 Salivary $\mathrm{pH}$ comparison among sample groups

\begin{tabular}{|c|c|c|c|c|c|c|c|}
\hline \multirow[b]{2}{*}{$\begin{array}{c}\text { salivary } \\
\text { sample }\end{array}$} & \multirow[b]{2}{*}{ Variables } & \multicolumn{2}{|c|}{ Group A } & \multicolumn{2}{|c|}{ Group B } & \multicolumn{2}{|c|}{ Group C } \\
\hline & & $\begin{array}{c}\text { Mean } \\
\text { pH } \\
\text { changes }\end{array}$ & p value & $\begin{array}{c}\text { Mean } \\
\text { pH } \\
\text { changes }\end{array}$ & p value & $\begin{array}{c}\text { Mean } \\
\text { pH } \\
\text { changes }\end{array}$ & p value \\
\hline Unstimulated & BASELINE & 6.66 & 00 & 6.64 & 00 & 6.66 & \\
\hline saliva & 15TH DAY & 6.96 & $.00<$ & 6.98 & .00 & 6.72 & 90 \\
\hline Stimulated & BASELINE & 7.04 & 004 & 6.84 & 00 & 7.04 & \\
\hline saliva & $15 \mathrm{TH}$ DAY & 7.38 & .004 & 7.30 & 004 & 7.10 & .953 \\
\hline
\end{tabular}

\section{DISCUSSION}

The results presented here as a pilot study in human adults, evidence that the use of lactic acid bacillus (A07FA01) contained in food commonly consumed and commonly prescribed probiotic oral capsules lowers the salivary levels of Sreptococcus mutans comparable to the fluoridated toothpaste and non fluoridated tooth paste. Incorporation of lactic acid bacillus (A07FA01) in an indigenous tooth paste preparation has been successfully validated in the present study and is one 
possible form of probiotic application. One possible side effect would be an increased production of organic acids in the dental plaque with the use of probiotic strains. Production of acids by microorganisms in the oral cavity is the direct causative factor for the demineralization of the tooth. ${ }^{4}$ Therefore we wanted to investigate if addition of probiotic lactobacilli to dental plaque would influence its acidogenicity.

The present study shows reduction in the acidogenicity of saliva after application of probiotic tooth paste with significant $p$ value of 0.004 . The results are in accordance with other similar study by Marttinen et al, where there was no increase in acidogenicity of plaque but significant increase in salivary $\mathrm{pH}$ levels was observed. ${ }^{5}$ Study done by SimarkMattsson et al showed similar reduction in acidogenecity and also demonstrated that low $\mathrm{pH}$ conditions may promote mutans streptococcus growth inhibition by probiotic lactobacilli. ${ }^{6}$ Controversially in other vitro studies L. reuteri DSM (ATCC 55730) and L. plantarum 299v lowered the $\mathrm{pH}$ significantly after fermentation of glucose and sucrose ${ }^{4,7}$. Thus acidogenicity of suspension of dental plaque and probiotic lactobacilli is strain-dependant. ${ }^{4}$ Similar to the Probiotic group, Fluoride group also showed significant reduction of acidogenicity with $p$ value $<0.01$. High fluoride concentration in the oral cavity might inhibit acid production by bacteria and may reduce the number of certain cariogenic species. ${ }^{8}$ The placebo group (plain indigenous tooth paste preparation) showed no significant changes in the $\mathrm{pH}$ level and no reduction in acidogenecity was observed in caries active patient samples thus ruling out the possibility of the placebo effect.

When used as an oral probiotic, it is desirable that the bacteria should have the ability to survive in saliva. ${ }^{5}$ The growth inhibition assay with MS strains isolated from cariessusceptible individuals showed growth inhibition of MS with selected Lactobacillus strains (A07FA01). ${ }^{3}$ The present study showed reduction of S.mutans from 125 to $32.4 \mathrm{CFU} / \mathrm{ml}$ of saliva with significant $p$ value of 0.001 . These results were supported by similar in vitro studies done by Haukioja et al 2006, Simark-Mattsson 2009 and keller et al 2011 showing that probiotic lactobacilli act as transient colonizers and competitive inhibitors of cariogenic strains. ${ }^{3,6,9}$ In vivo study done by Ahola et al 2002 showed reduction in Streptococcus mutans count after 3 weeks application of lactobacilli mix. ${ }^{10}$ Similar study done by Nikawa et al 2004 also showed reduction in $\mathrm{S}$ mutans in two weeks crossover study. ${ }^{11}$ Study done by Singh et al 2011 using L. acidophilus La5 Bifidobacterium lactis Bb-12 application for 10 days also showed similar results. ${ }^{12}$ Study done by Chuang et al 2011 using L. paracasei GMNL-33 application for 2 weeks showed similar results. ${ }^{13}$

Topical fluoride application in the present study also yielded similar results with significant reduction $\mathrm{S}$ mutans from 103 to $34 \mathrm{CFU} / \mathrm{ml}$ of saliva ( $\mathrm{p}$ value 0.006 ) after 15 days application. Songpaisan et al. reported low counts of Streptococcus mutans in children using $0.5 \%$ hydrofluoride solution. ${ }^{14}$ Berg et al. and Forss et al. have found that the plaque adjacent to fluoride-releasing glass ionomers demonstrate lower levels of Streptococcus mutans. ${ }^{15}$, 16 Yoshiara et al. found that the long-term use of a fluoride mouth rinse might contribute to the reduction of mutans streptococci. ${ }^{17}$ Comparison between fluoride and probiotic group were statistically insignificant both the groups yielding similar results. In Placebo group reduction in $\mathrm{S}$ mutans was insignificant, thus ruling out the possibility of placebo effect. The reduction of Mitis Streptococcus can be considered as a surrogate measure for a caries-preventive effect. Though MS is important it is not the only microorganism in the pathogenesis of dental caries. As dental caries usually develops over a long period, it is handy to measure MS fluctuations for study purposes.

\section{CONCLUSION}

The result achieved in the present study is tremendously interesting and provides some answers which motivates us for future researches in large perspective. This complex interactions probiotics against the bacteria in the biofilm and the development of an aciduric biofilm, which is able to cause disease, is the concept that has to be analyzed in large scale molecular levels to come out with promising results. In the present study, the impact of Lactobacillus strain (A07FA01) in reducing streptococcus mutans $\mathrm{CFU} / \mathrm{ml}$ of saliva was promising and comparable with the currently prescribed anticaries fluoride tooth paste. Fluoride being a double edged sword with many systemic adverse effects on long term use, its consumption can be replaced by probiotics in near future if large scale studies yields promising results. Thus probiotics lactobacillus strains can be a possible effective anticaries medicament in future.

\section{References}

1. Marsh PD, Devine DA. How is the development of dental biofilms influenced by the host? J Clin Periodontol 2011; 38 (Suppl. 11): 28-35.

2. Haukioja A, Loimaranta V, Tenovuo J. Probiotic bacteria affect the composition of salivary pellicle and streptococcaladhesion in vitro. Oral Microbiol Immunol 2008; 23(4): 336-43.

3. Haukioja A, Yli-Knuuttila H, Loimaranta V, Kari K, Ouwehand $\mathrm{AC}$, Meurman $\mathrm{JH}$, et al. Oral adhesion and survival of probiotic and other lactobacilli and bifidobacteria in vitro. Oral Microbiol Immunol 2006; 21(5): 326-32.

4. Hedberg M, Hasslöf $P$, Sjöström I, Twetman S, Stecksen-Blicks C: Sugar fermentation in probiotic bacteria-an in vitro study. Oral Microbiol Immunol 2008, 23:482-485.

5. Marttinen A, Haukioja A, Karjalainen S, Nylund L, Satokari R, Öhman C, et al: Short-term consumption of probiotic lactobacilli has no effect on acid production of supragingival plaque. Clin Oral Investig 2011, 16:797-803.

6. Simark-Mattsson C, Jonsson R, Emilson CG, Roos K: Final $\mathrm{pH}$ affects the interference capacity of naturally occurring oral Lactobacillus strains against mutans streptococci. Arch Oral Biol 2009, 54:602-607.

7. Haukioja A, Söderling E, Tenovuo J: Acid production from sugars and sugar alcohols by probiotic lactobacilli and bifidobacteria in vitro. Caries Res 2008, 42:449453

8. Hamilton IR. Biochemical effects of fluoride on oral bacteria. J Dent Res 1990; 69: 660- 7.

9. Keller MK, Hasslöf P, Stecksén-Blicks C, Twetman S: Co-aggregation and growth inhibition of probiotic lactobacilli and clinical isolates of mutans streptococci: 
an in vitro study. Acta Odontol Scand 2011, 69:263268.

10. Ahola, A. J., Y, H., Suomalainen, T., Poussa, T., Ahlstrom, A., Meurman, J. H. \& Korpela, R. 2002. Shortterm consumption of probiotic-containing cheese and its effect on dental caries risk factors. Arch Oral Biol, 47, 799-804.

11. Nikawa, H., Makihira, S., Fukushima, H., Nishimura, H., Ozaki,Y. Ishida, K., Darmawan, S., Hamada, T., Hara, K.,Matsumoto, A., Takemoto, T \& Aimi, R. 2004. Lactobacillus reuteri in bovine milk fermented decreases the oral carriage of mutans streptococci. Int $J$ Food Microbiol, 95, 219- 23.

12. Singh, R. P., Damle, S. G. \& Chawla, A. 2011. Salivary mutans streptococci and lactobacilli modulations in young children on consumption of probiotic ice-cream containing Bifidobacterium lactis Bb12 and Lactobacillus acidophilus La5. Acta Odontol Scand, 69, 389-94.
13. Chuang L. C., Huang, C. S., Ou- Yang, L.W. \& Lin, S. Y. 2011. Probiotic Lactobacillus paracasei effect on cariogenic bacterial flora. Clin Oral Investig, 15, 4716.

14. Songpaisan Y, Serinirarch R, Kuvatanasuchati J, Bratthal D. Mutans streptococci in Thai population: Relation to caries and changes in prevalence after application of fissure sealants. Caries Res 1994; 28: 74-9.

15. Berg JH, Farrel JE, Brown LR. Class II glass ionomer/ silver cement restorations and the effect on interproximal growth of mutans streptococci. Pediatr Dent 1990; 12: 20- 3.

16. Forss H, Jokinen J, Spets-Happonen S, Seppa L, Luoma H. Fluoride and mutans streptococci in plaque grown on glass ionomer and composite. Caries Res 1991; 25: 454- 8.

17. Yoshiara A, Sakuma S, Kobayashi S, Miyazaki H. Antimicrobial effect of fluoride mouth rinse on mutans streptococci and lactobacilli in saliva. Pediatr Dent 2001; 23: 113-7.

\section{How to cite this article:}

Nandhinim V et al (2017) ' Comparative Study Of Topical Effects Of Probiotics With A Commercial Fluoride Tooth Paste In Reducing Dental Caries In Patients With Higher Salivary Streptococcus Mutans Levels', International Journal of Current Advanced Research, 06(04), pp. 3225-3228. 